\title{
A (2X1) ARRAY ANTENNA DESIGN FOR 24 GHZ APPLICATION
}

\author{
${ }^{1}$ V. CHINNAMMAL \& ${ }^{2}$ P. JOTHILAKSHMI \\ ${ }^{I}$ Assistant Professor, Rajalakshmi Institute of Technology, Tamil Nadu, India \\ ${ }^{2}$ Professor, Sri Venkateswara College of Engineering, Tamil Nadu, India
}

\begin{abstract}
The goal is to design as well as to simulate a microstrip patch antenna by means of inset feeding technique. It has two array elements and is constructed by means of FR-4 (Flame Retardant-4) substrate. This has permittivity of 4.4 and the height of $1.6 \mathrm{~mm}$. The array (2x1) elements are designed for the frequency of $24 \mathrm{GHz}$. The microstrip patch antenna is of rectangular shape. The CST microwave studio tool is employed for construction of patch array antenna. The planned antenna has constructed and simulated outcomes like Return loss, VSWR, directivity and gain are attained effectively.

KEYWORDS: Microstrip Patch, Inset Feed, FR-4, Rectangular Patch, CST Tool
\end{abstract}

Received: Jun 01, 2020; Accepted: Jun 20, 2020; Published: Jul 10, 2020; Paper Id.: IJMPERDJUN2020275

\section{INTRODUCTION}

To attain the power emission model, an array of Microstrip Patch Antenna (MPA) is employed but this could not be attained by a single MPA. The directivity and gain of the aerial becomes enhanced by means of an array patch aerial. If the series method of feed is employed to an array then it has meager directive gain and high return loss but it needs low area while corporate feed in an array gives moderately high efficiency, less return loss and it needs a larger area. When these dual methods are joined together in an array and named as corporate-series feed method that gives moderate return loss and needs an average area for feeding.

The enhancement of inter-element spacing creates the main lobe of the radiation pattern as a narrower and enhances the number of minor lobes in the array of MPA. The position of the main beam is steered by commencing a phase difference in the input to the array patch elements. The directivity and gain gets enhanced by the linear microstrip patch antenna array but the beam could be steered only in one dimension. Whereas the planar Microstrip patch antenna array gives moderately high directivity and gain as compared with a single microstrip patch antenna but meager as compared with linear arrays and it makes the antenna to steer the beam in any direction.

Two types of feeding methods namely contact method and non-contact method. The microstrip line feed and coaxial probe feed belongs to contact method and aperture coupling and proximity coupling belongs to non-contact method.

High gain is needed for the millimeter-wave (mm-wave) communications. Thus to attain high gain antenna arrays are favored. The most important concern of the antenna array is less profile, conformal installation, weight, size and cost effective. Particularly, the gain and impedance bandwidth would have great adverse effects at mmwave frequency or in Ka-Band as compared the lower frequencies.

In this proposed work, a microstrip patch antenna is designed which is usually rectangular, circular, triangular and square and other shapes. Mainly, the rectangular shape is broadly used. The performance of antenna is determined by the shape, substrate, material, dimensions and feed type of the antenna. 
The flow of this work is organized as follows-- firstly, the design of 2-element array (2×1) with an inset feed technique is presented in section 2. In section 3, the simulated outcomes are displayed and in section 4, the conclusion is drawn.

\section{Antenna Design}

The microstrip patch antenna array is designed and simulated. The software tool employed is CST Studio. The designed microstrip antenna array has rectangular shaped patch as illustrated in the figure 1 and the figure 2 reveals the front sight of an array antenna.

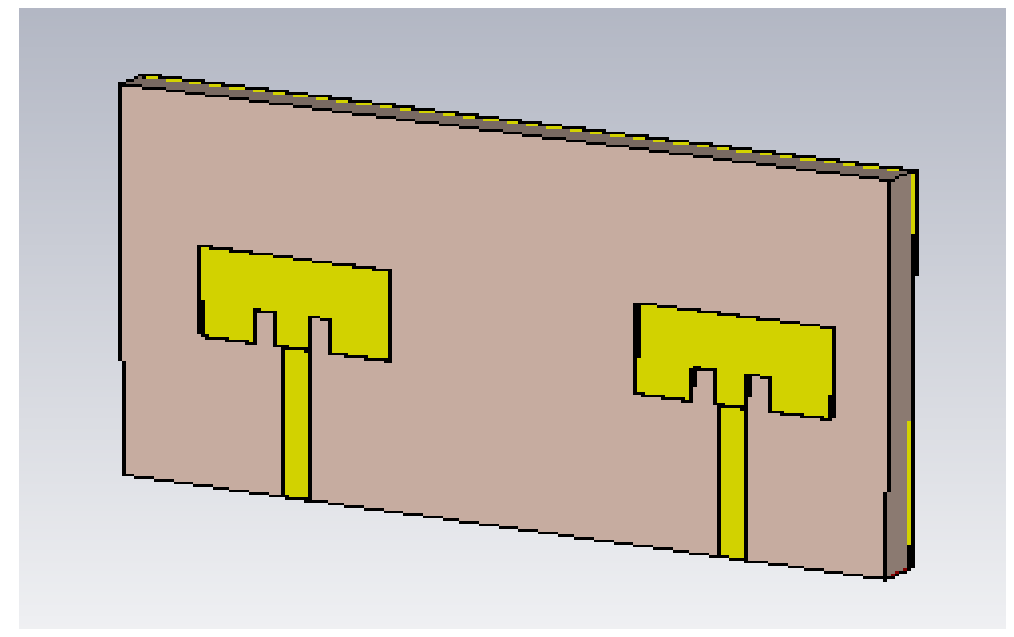

Figure 1: Layout of an Array Antenna.

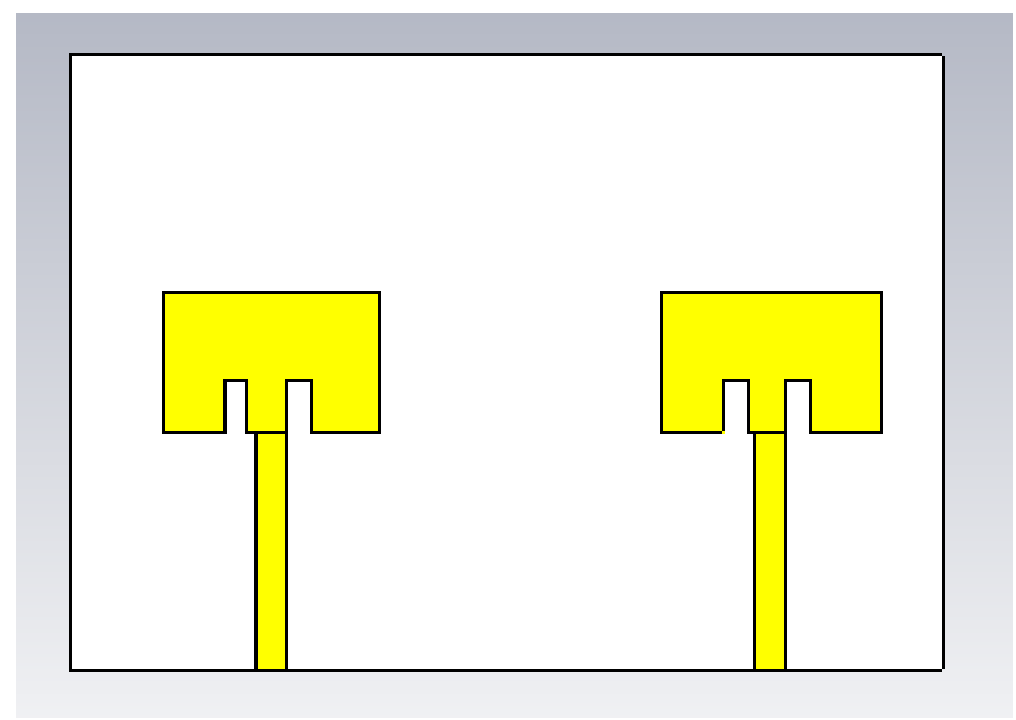

Figure 2: Front Sight of Array Antenna.

The single patch antenna has been designed to operate at resonant frequency of $24 \mathrm{GHz}$ with input impedance of $50 \Omega$ using FR4 substrate with $\varepsilon_{\mathrm{r}}=4.4$, loss tangent $\delta=0.02$ and thickness $\mathrm{h}=1.6 \mathrm{~mm}$. FR-4 is used as the substrate material because of the low cost and easy to fabricate. The single patch antenna is transformed into another patch with the separation of $10 \mathrm{~mm}$. The patch antenna parameters are calculated from the standard antenna design equations and the dimensional values are given in Table 1. 
Table 1: Antenna Dimensions

\begin{tabular}{|l|c|}
\hline \multicolumn{1}{|c|}{ Parameters } & Dimensions (mm) \\
\hline Width of the patch (W) & 7 \\
\hline Length of the patch (L) & 4.6 \\
\hline Inset feed point (H) & 1.7 \\
\hline Width of the feed line ( Wf) & 1 \\
\hline Gap of the feed line ( g) & 0.20558 \\
\hline Length of ground (Lg) & 20 \\
\hline Width of ground $(\mathrm{Wg})$ & 28 \\
\hline
\end{tabular}

\section{Simulated Outcomes}

Once the design and simulation of the proposed antenna array using CST has been completed and then 2-element ( $2 \times 1)$ rectangular microstrip patch array antenna with inset feeding networks are analyzed. The simulation outcomes like Return loss, VSWR, directivity and gain of proposed antenna designs are computed. The figure 3 and figure 4 reveals the return loss and VSWR of the antenna array. The attained values of return loss and VSWR are $-53.93 \mathrm{~dB}$ and 1.04 at the frequency of $24 \mathrm{GHz}$.

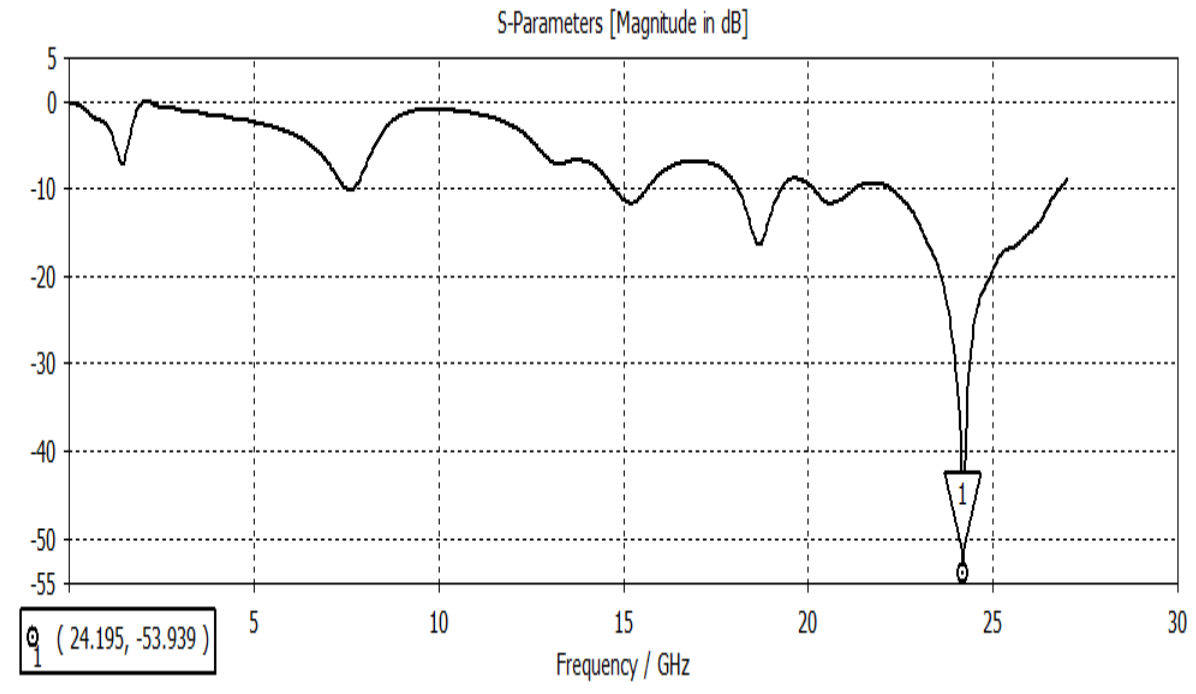

Figure 3: Return Loss of the Antenna Array.

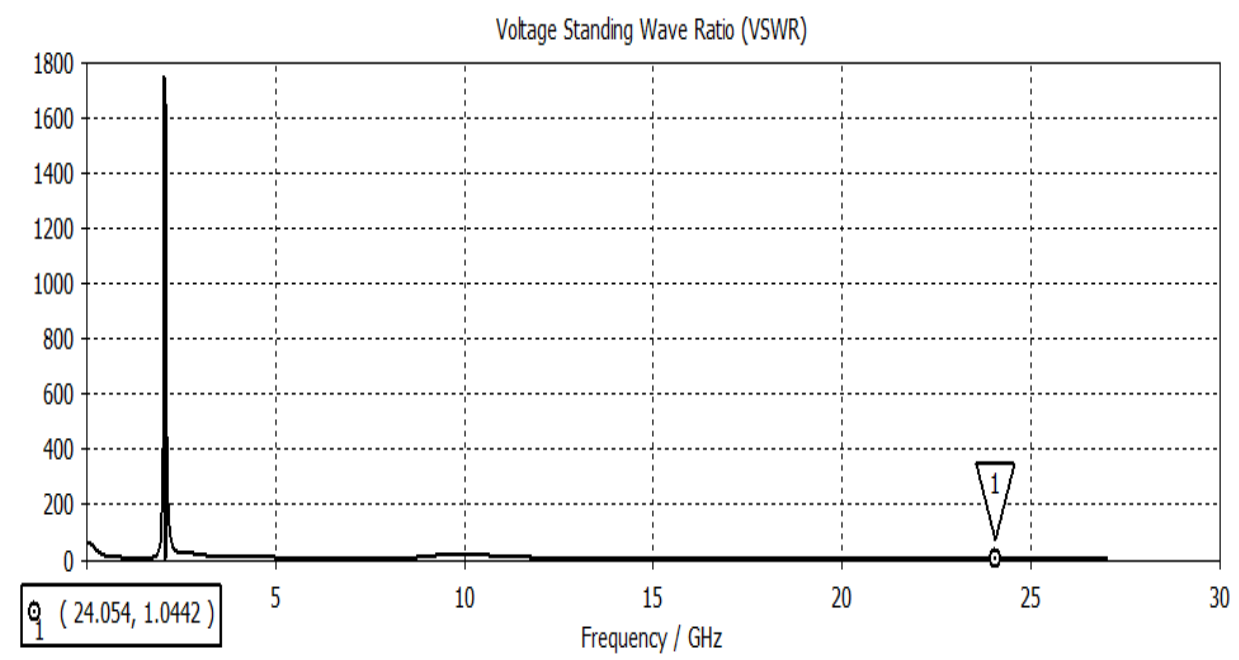

Figure 4: VSWR of the Antenna Array. 
The three dimensional plots of the directivity and gain are revealed in the figure $5 \&$ figure 6 . The attained values of directivity and gain are $6.62 \mathrm{dBi}$ and $3.67 \mathrm{~dB}$ at $24 \mathrm{GHz}$ correspondingly.

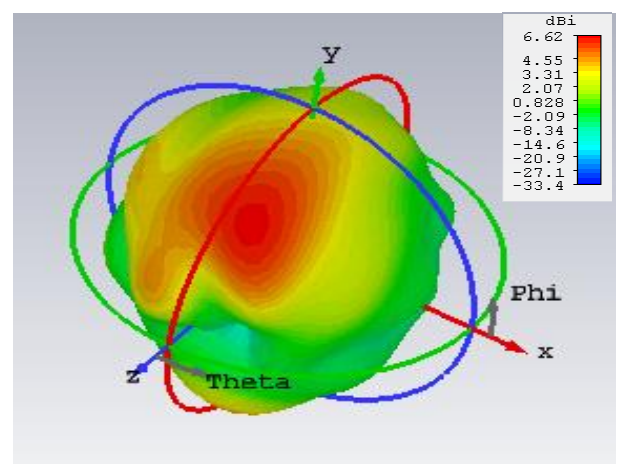

Figure 5: Directivity of the Antenna Array.

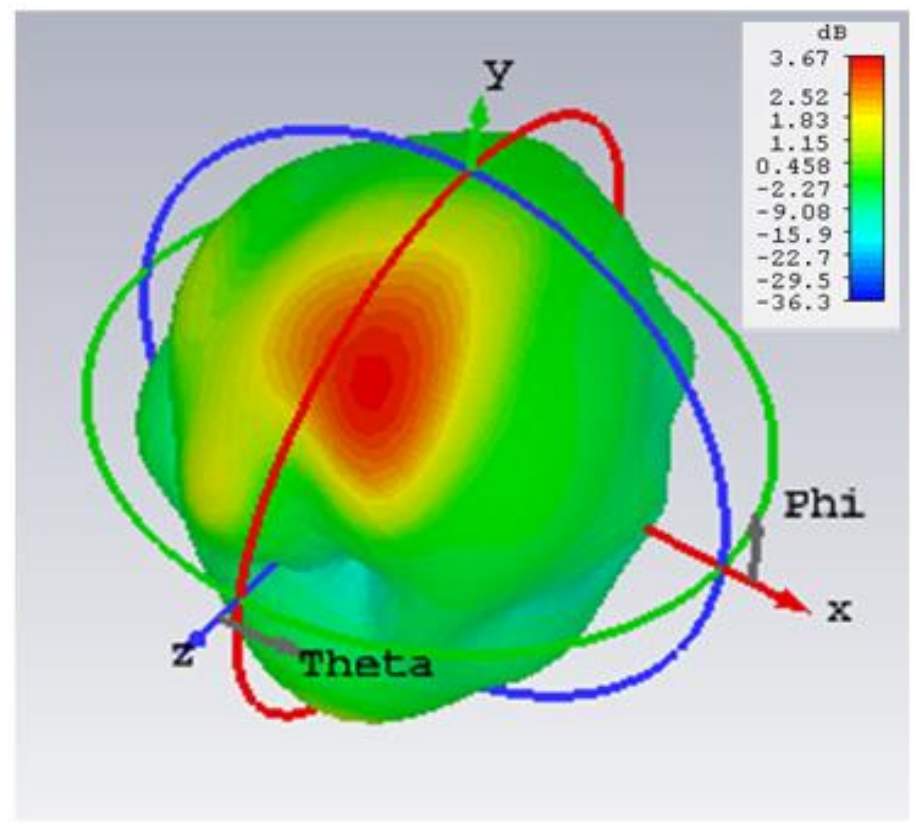

Figure 6: Gain of the Antenna Array.

The far field plots of directivity and gain are illustrated in the figure 7 and figure 8 . 
Farfield Directivity Abs (Phi=90)

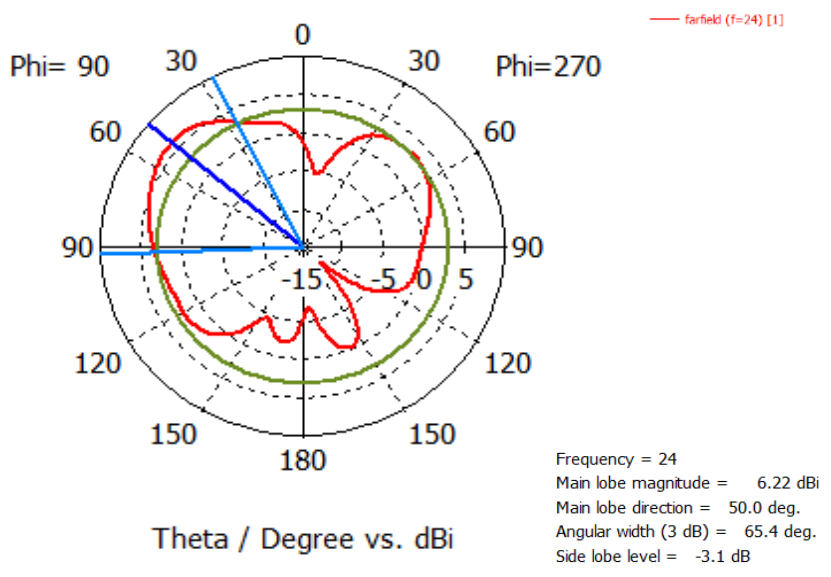

Figure 7: Far field Directivity at 24GHz.

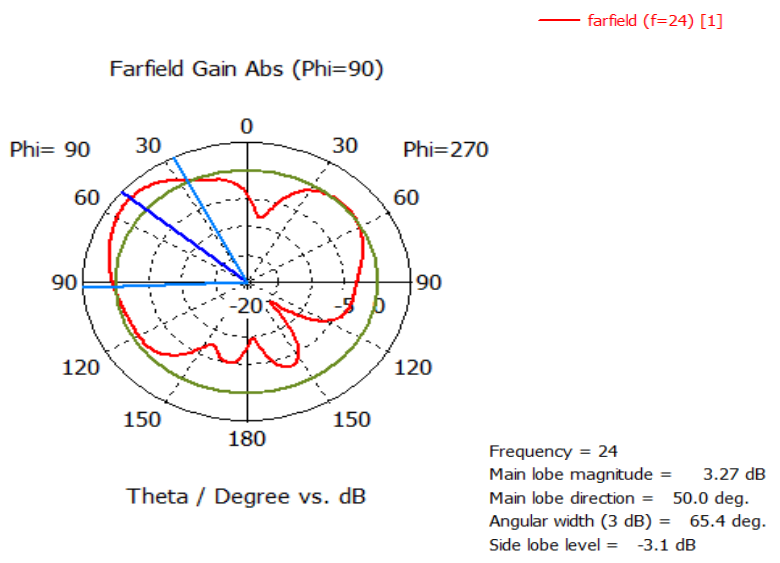

Figure 8: Far Field Gain at 24 GHz.

\section{CONCLUSIONS}

The $2 \times 1$ rectangular patch antenna arrays have been designed using inset feeding technique having same patch dimension and simulated using CST Microwave Studio software. The Return Loss, VSWR, Directivity and Gain have been computed. Since the choice of choosing the feeding technique for a microstrip patch antenna plays a vital part as it affects the return loss, VSWR, gain and other parameters. It is employed for K band applications. The $2 \times 1$ patch antenna array reveals better gain performance and radiation characteristics at resonance frequencies as compared to a single patch antenna. 


\section{REFERENCES}

1. Balanis, C. A., Antenna Theory Analysis and Design, Wiley \& Sons Ltd, New Jersy, 2005.

2. Huang, Y. and K. Boyle, Antennas from Theory to Practice, Wiley \& Sons Ltd, West Sussex, 2008.

3. Constantine A. Balanis, “Antenna Theory”, 3rd ed., Wiley- India publications.

4. John D. Kraus, Ronald J. Marhefka, Ahmad S. Khan, “Antennas and Wave Propagation”, 4th ed., Tata McGraw Hill Education Pvt. Ltd.

5. Microstrip Antennas: "The Analysis and Design of Microstrip Antennas and Arrays," David M. Pozar and Daniel H. Schaubert, Editors, Wiley/IEEE Press, 1995

6. Deschamps, G.A., Microstrip microwave antennas, " Proceedings of Third USAF Symposium on Antennas, 1953.

7. J. G. Vera-Dimas, M. Tecpoyotl-Torres, P. Vargas-Chable, J. A. Damián-Morales J. Escobedo-Alatorre and S. Koshevaya, "Individual patch antenna and antenna patch array for wi-fi communication" Center for Research of Engineering and Applied Sciences (CIICAp), Autonomous University of Morelos State (UAEM), 62209, Av. Universidad No.1001, Col Chamilpa, Cuernavaca, Morelos, México.

8. Bahadir S. Yildirim, Bedri A. Cetiner, et al, "Integrated bluetooth and uwb antenna", IEEE antennas \& wireless propag. letters, vol. 8, 2009.

9. Low Ching Yu and Muhammad Ramlee Kamarudin, "Investigation of Patch Phase Array Antenna Orientation at 28 GHzfor $5 G$ Applications”, iEECON2016, Elsevier Procedia Computer Science, Volume 86, pp. 47 - 50, (2016).

10. Mohamed, Mashade, Ehab.A.Hegazy, "Design and Analysis of Rectangular Microstrip Patch Array Antenna for Fifth Generation of Mobile Technology”, SF J Telecommunic 1:1, 2017.

11. E.Praveenkumar, Dr.B.Paulchamy, S.Mohanraj, S.Mohan, "Design of $1 x 8$ phased array microstrip patch antenna for biomedical application" International Conference on Explorations and Innovations in Engineering \& Technology, 2016.

12. R.Thandaiah Prabu, R.Ranjeetha, V.Thulasi Bai, "Design of Alpha/Numeric Microstrip Patch Antenna for Wi-Fi Applications", Data Engineering and Intelligent Computing, Advances in Intelligent Systems and Computing 542, ISBN: 978981-10-3222-6, (DOI 10.1007/978-981-10-3223-3_3), 2017.

13. Qi Wu, Ronghong Jin, and Junping Geng "A single-layer ultrawideband microstrip antenna” IEEE trans. on antennas \& propag., vol. 58,no. 1, January 2010.

14. D.Koria, K.Ratho, A.Khandagale, J.Kosambi, H.Jain "Performance comparison of microstrip array antenna with single microstrip antenna", International Journal of Current Trends in Engineering \&Research (IJCTER), e-ISSN 2455-1392, Volume 2 Issue 4, April 2016 pp. 349 - 355.

15. V. R. Anitha, S. Narayana Reddy, "Design of an $8 \times 1$ square microstrip patch antenna array”, International Journal of Electronic Engineering Research, Vol. 1. No. 1, 2009, pp. 71-77.

16. Akki, Vishnu Vardhan Reddy, And Gurpreet Kumar. "DGS Based Frequency Reconfigurable Microstrip Patch Antenna for Cognitive Radio and WI-Max Applications." International Journal of Electronics and Communication Engineering(IJECE) (2016): 51-60

17. Sharma, Sushant, and Gurpreet Kumar. "A dual Wideband Stair Shape Microstrip Patch Antenna for C \& X Band." International Journal of Electronics and Communication Engineering (IJECE) 5.4 (2016): 1-8. 
18. Kashyap, S. Sreenath, And Ved Vyas Dwivedi. "Numerical Analysis and Modelling of Microstrip Patch Antennas with Embedded Defective Ground Structure." International Journal of Electrical and Electronics Engineering(IJEEE) 5-4 (2016): 9-18

19. Varaprasad, S. Phani, and R. Prasad Rao. "Design and Analysis of a Multi Layer Substrate Single Patch Microstrip Patch Antenna for Enhancing the Beam Width with Control on Directivity." International Journal of Electronics and Communication Engineering(IJECE) 6-1 (2017): 47-52

20. Maurya, Rakesh Kumar, Ajay Kumar Maurya, and Rabindra Kumar Singh. "Artificial Neural Network Model for Analysis of Elliptical Microstrip Patch Antenna." IMPACT : International Journal of Research in Engineering \& Technology 2-4 (2014): 185-192

21. Agrawal, Akash, Narendra Kumar Garg, and Rahul Sharma. "Accretion in Parameters of Rectangular Microstrip Patch Antenna with Metamaterial." International Journal of Research in Engineering \& Technology 2-10 (2014): $39-46$ 
